FARIA RT; TAKAHASHI LSA; LONE AB; SOUZA GRB; SILVA GL; HOSHINO RT. 2013. UEL 8: nova cultivar de Dendrobium. Horticultura Brasileira 31: 509-511.

\title{
UEL 8: nova cultivar de Dendrobium
}

\author{
Ricardo T de Faria; Lúcia SA Takahashi; Alessandro B Lone; Gilberto RB de Souza; Geraldo L da Silva; \\ Rodrigo T Hoshino \\ UEL, Depto. Agronomia, C. Postal 6001,86051-990 Londrina-PR; faria@uel.br
}

\begin{abstract}
RESUMO
UEL 8 é uma cultivar de Dendrobium nobile, desenvolvida no Departamento de Agronomia da Universidade Estadual de Londrina, resultante do cruzamento das plantas matrizes D14 x D7 e selecionada pelo tamanho das flores e por apresentar florescimento intenso e uniforme. As plantas foram polinizadas artificialmente e as sementes germinadas in vitro. A cultivar UEL 8 apresenta flores de coloração roxa, sendo o labelo, na porção inferior, da mesma tonalidade dos outros verticilos florais, a parte mediana branca e a região mais interna de um roxo intenso, escuro e de textura aveludada; cada pseudobulbo apresenta, em média, 34 flores. As flores têm durabilidade de, aproximadamente, 20 dias.
\end{abstract}

Palavras-chave: Hibridação, melhoramento, orquídea, seleção.

\begin{abstract}
UEL 8: a new Dendrobium cultivar

UEL 8 is a cultivar of Dendrobium nobile developed in the Department of Agronomy, Universidade Estadual de Londrina resulting from the crossing of matrix plants D7 and D14 selected by the size of the flowers that have intense and uniform flowering. The plants were artificially pollinated and the seeds sown in vitro. The cultivar has flowers of purple color, and the lip on the lower portion presents the same shade of the other whorls, the middle part is white and the inner part presents a deep purple color, dark and velvety texture. The pseudobulb has on average 34 flowers with a life span of about 20 days.
\end{abstract}

Keywords: Hybridization, breeding, orchid, selection.

(Recebido para publicação em 22 de fevereiro de 2013; aceito em 5 de junho de 2013)

(Received on February 22, 2013; accepted on June 5, 2013)

A floricultura comercial representa um importante segmento do agronegócio brasileiro contemporâneo. $\mathrm{O}$ faturamento do setor em 2011 foi da ordem de $\mathrm{R} \$ 4,3$ bilhões em nível de consumidor final e o crescimento estimado em 12\% em 2012 (Ibraflor, 2013a).

O fortalecimento do comércio interno e para o exterior dos produtos da floricultura brasileira, constitui uma ação relevante para a garantia de um grande número de empregos no campo e nas cidades e, inclusive, à sobrevivência de inúmeras propriedades e empresas agrícolas (Junqueira \& Peetz, 2011). Aliado a isso, a comercialização em supermercados, feiras e eventos tem criado a necessidade de novas variedades e híbridos de plantas (Takane et al., 2010).

São escassos os trabalhos de melhoramento genético de orquídeas no Brasil devido ao ciclo longo das plantas. No gênero Dendrobium, o ciclo leva, em média, quatro anos da polinização até o florescimento. Dentro desse gênero, Dendrobium nobile é uma espécie de folha renovável com muitas cultivares. Os caules, eretos, atingem $30-40 \mathrm{~cm}$ de altura, com grupos de duas a três flores por nó e cerca de $7,0 \mathrm{~cm}$ de diâmetro (Suttleworth et al., 1994).

Segundo os critérios de classificação de Dendrobium em vaso, as plantas devem possuir entre 30 a $80 \mathrm{~cm}$ de altura, maturação uniforme e uma quantidade mínima de 10 flores por haste. O número de hastes está ligado à valorização do produto, devendo as plantas serem isentas de defeitos como danos de doenças e pragas (Ibraflor, 2013b).

Para seleção de plantas ornamentais com qualidade superior, são consideradas as características ornamentais tais como coloração, tamanho e proporcionalidade das flores e vigor vegetativo. Dentre as características agronômicas, estão o crescimento e florescimento rápido, durabilidade das flores, resposta à adubação, facilidade de cultivo, resistência a pragas e doenças, adaptabilidade às diferentes regiões de cultivo e o aspecto inovador da cultivar, o que a torna interessante comercialmente (Cardoso, 2010).

O objetivo do trabalho foi a obtenção de uma nova cultivar de $D$. nobile a partir de cruzamentos realizados entre matrizes selecionadas.

\section{MÉTODO DE MELHORA- MENTO}

A cultivar UEL 8 foi obtida no Departamento de Agronomia da Universidade Estadual de Londrina (UEL), o qual lançou as cultivares UEL 6 e UEL 7 (Faria et al., 2009, 2011).

As plantas matrizes de Dendrobium nobile (Orchidaceae) utilizadas foram obtidas de produtores da Holambra- 


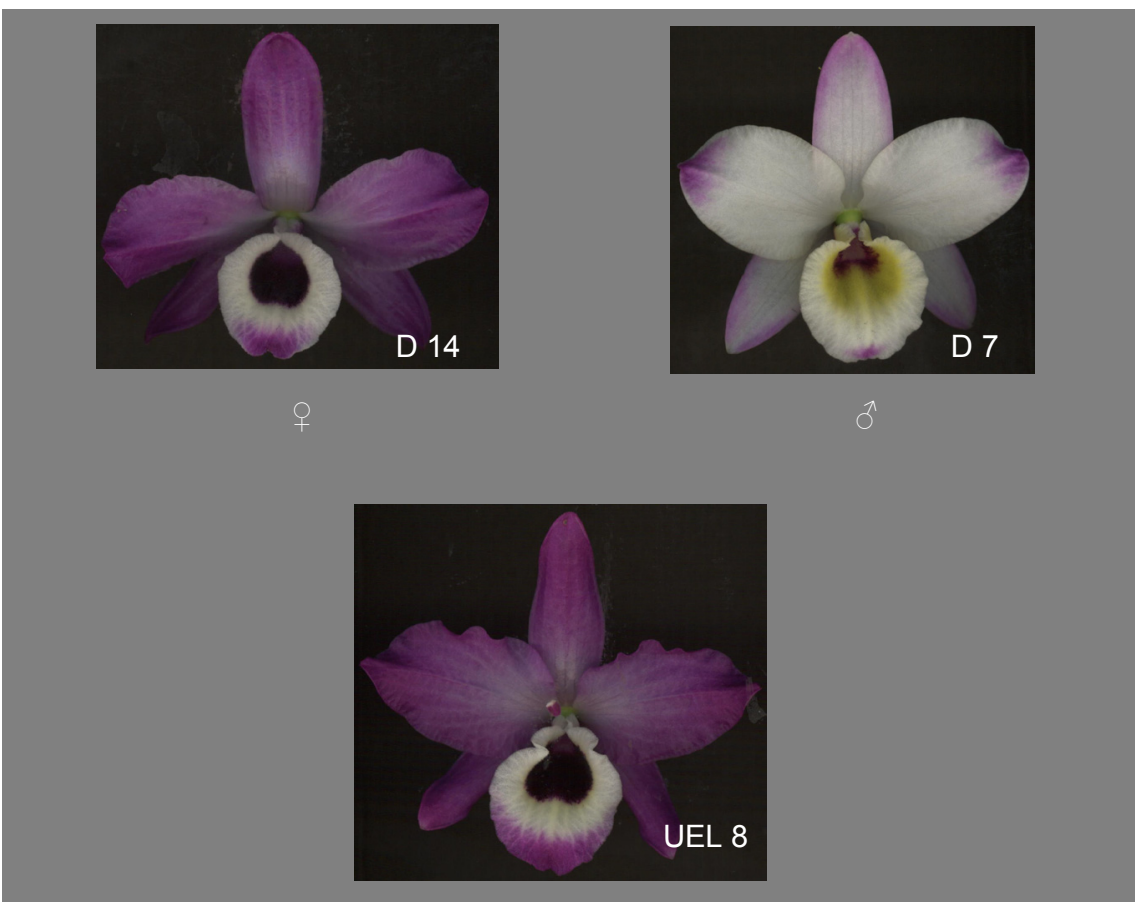

Figura 1. Flores dos genótipos parentais (D14 e D7) e da cultivar UEL 8 [fowers of parental genotypes (D14 and D7) and of UEL 8 cultivar]. Londrina, UEL, 2013.

SP e selecionadas de acordo com características comerciais tais como coloração, número de flores, porte da planta, época de florescimento e tamanho das flores. Foram utilizadas 15 matrizes de Dendrobium nobile para a realização dos cruzamentos.

As flores foram polinizadas artifi- cialmente e, após nove meses, obtidas as cápsulas contendo as sementes dos cruzamentos, as quais foram germinadas em meio de cultura MS (Murashige \& Skoog, 1962) modificado com a metade da concentração dos macronutrientes (Rego-Oliveira \& Faria, 2005). As plântulas obtidas no processo de germinação foram transportadas em mesmo meio de cultura com 10 a 12 plantas por frasco sob fotoperíodo de 16 horas de luz (lâmpada fluorescente) e temperatura de $25 \pm 2^{\circ} \mathrm{C}$.

A aclimatização ocorreu em estufa plástica com $60 \%$ de sombreamento obtido por tela de polipropileno de cor preta em bandejas de isopor $(25 \times 25 \mathrm{~cm})$, utilizando esfagno como substrato, onde permaneceram durante dois meses. Após este período, foi feito o transplantio para vasos plásticos pretos com diâmetro de $10,2 \mathrm{~cm}$, altura de $7,8 \mathrm{~cm}$ e volume de $415 \mathrm{~mL}$, onde permaneceram durante seis meses até atingirem, aproximadamente, $12 \mathrm{~cm}$ de altura. Após isso, foi feito o transplantio para vasos plásticos pretos com diâmetro de $13 \mathrm{~cm}$, altura de $9,8 \mathrm{~cm}$ e volume de $1000 \mathrm{~mL}$, permanecendo até o florescimento. O substrato utilizado foi a casca de pinus, segundo Faria et al. (2010).

Os tratos culturais constaram da retirada manual de plantas daninhas, regas em dias alternados e utilização de fungicidas e inseticidas quando necessário. Foi realizada adubação foliar mensal com $3 \mathrm{~g} \mathrm{~L}^{-1}$ da fórmula 10-30$20\left(\right.$ Peters $\left.^{\circledR}\right)$ na fase de aclimatização e $5 \mathrm{~mL} \mathrm{~L}^{-1}$ da fórmula 08-09-09 (Biofert Plus $^{\circledR}$ ) a cada 15 dias na fase de desenvolvimento das plantas.

Tabela 1. Frequência de plantas com flores, número médio de flores por pseudobulbo e tamanho médio das flores e dos labelos, resultantes dos cruzamentos de Dendrobium nobile (frequency of flowering plants, average number of flowers per pseudobulb and average size of flowers and lips, resulting from crosses of Dendrobium nobile). Londrina, UEL, 2013.

\begin{tabular}{|c|c|c|c|c|c|c|}
\hline \multirow{2}{*}{$\begin{array}{l}\text { Cruzamentos } \\
\text { (Parentais ) }\end{array}$} & \multirow{2}{*}{$\begin{array}{l}\text { Frequência de } \\
\text { plantas com flores }\end{array}$} & \multirow{2}{*}{$\begin{array}{l}\text { Número de flores } \\
\text { por pseudobulbo }\end{array}$} & \multicolumn{2}{|c|}{ Tamanho da flor $(\mathrm{cm})$} & \multicolumn{2}{|c|}{ Tamanho do labelo $(\mathrm{cm})$} \\
\hline & & & Largura & Comprimento & Largura & Comprimento \\
\hline \multicolumn{7}{|l|}{ ㅇ } \\
\hline D3 x D8 & $100 a^{*}$ & $11 \mathrm{c}$ & $7,0 \mathrm{~b}$ & $6,9 \mathrm{~b}$ & $2,5 \mathrm{~b}$ & $3,2 \mathrm{~b}$ \\
\hline D5 x D9 & $50 \mathrm{c}$ & $21 \mathrm{~b}$ & $5,7 \mathrm{~d}$ & $5,2 \mathrm{~d}$ & $1,9 \mathrm{c}$ & $2,4 \mathrm{c}$ \\
\hline D6 x D9 & $80 \mathrm{~b}$ & $31 \mathrm{a}$ & $5,1 \mathrm{~d}$ & $4,4 \mathrm{e}$ & $1,8 \mathrm{c}$ & $2,1 \mathrm{c}$ \\
\hline D6 x D15 & $81 \mathrm{~b}$ & $30 \mathrm{a}$ & $6,3 \mathrm{c}$ & $5,0 \mathrm{~d}$ & $2,0 \mathrm{c}$ & $2,5 \mathrm{c}$ \\
\hline D7 x D14 & $83 \mathrm{~b}$ & $20 \mathrm{~b}$ & $6,7 \mathrm{c}$ & $6,3 \mathrm{c}$ & $1,8 \mathrm{c}$ & $2,9 \mathrm{~b}$ \\
\hline D14 x D7 & $100 \mathrm{a}$ & $34 \mathrm{a}$ & $8,2 \mathrm{a}$ & $7,7 \mathrm{a}$ & $4,2 \mathrm{a}$ & $4,8 \mathrm{a}$ \\
\hline D9 x D2 & $86 \mathrm{~b}$ & $26 \mathrm{~b}$ & $4,1 \mathrm{e}$ & $3,4 \mathrm{f}$ & $1,3 \mathrm{~d}$ & $1,7 \mathrm{~d}$ \\
\hline D9 x D7 & $100 \mathrm{a}$ & $31 \mathrm{a}$ & $5,1 \mathrm{~d}$ & $4,6 \mathrm{e}$ & $2,6 \mathrm{~b}$ & $3,1 \mathrm{~b}$ \\
\hline $\mathrm{CV}(\%)$ & 12,57 & 22,63 & 7,66 & 10,73 & 10,53 & 10,52 \\
\hline
\end{tabular}

Médias seguidas de mesma letra não diferem entre si significativamente pelo teste de Scott Knott a 5\% de probabilidade. Dados de frequência transformados pela equação: arco-seno $(\mathrm{x} / 100)^{1 / 2}$ (means followed by the same letter do not differ significantly by the Scott Knott test at $5 \%$ probability. Frequency data processed by the equation: arcsine $\left.(\mathrm{x} / 100)^{1 / 2}\right)$. 
Foram selecionadas 20 plantas por cruzamento, das quais foram avaliados o comprimento do pseudobulbo, o comprimento e a largura das flores e do labelo, a frequência de florescimento, o número de flores por pseudobulbo e a durabilidade das flores. Para a avaliação das características fitométricas das flores foi utilizada uma flor por vaso. $\mathrm{O}$ florescimento foi considerado o período entre a abertura dos primeiros botões até o início do murchamento. A durabilidade das hastes foi avaliada em condições de laboratório, onde a temperatura no ambiente variou de 19 a $27^{\circ} \mathrm{C}$ e a umidade relativa do ar permaneceu entre 30 e $50 \%$, mantido em fotoperíodo de 16 horas de luz (lâmpada fluorescente).

\section{CARACTERÍSTICAS}

Durante os anos de 2011 e 2012, entre os meses de agosto e setembro, floresceram oito cruzamentos: D3 x D8, D5 x D9, D6 x D9, D6 x D15, D7 x D14, D14 x D7, D9 x D2 e D9 x D7 (Tabela 1). Dentre eles a UEL 8 (Figura 1) apresentou maior frequência de plantas com flores, número médio de flores por pseudobulbo, tamanho médio das flores e dos labelos (Tabela 1).

UEL 8 é originada das plantas matrizes D14 x D7, sendo selecionada pelo tamanho das flores e por apresentar florescimento intenso e uniforme (Tabela 1). É uma planta vigorosa de pseudobulbos com altura média de $45 \pm 4,2 \mathrm{~cm}$. As flores possuem uma co- loração roxa predominante. As sépalas e pétalas laterais possuem uma nuance tendendo a apresentar coloração mais clara no centro. O labelo apresenta três cores distintas com limites bem visíveis, sendo a porção inferior da mesma tonalidade dos outros verticilos florais, a parte mediana branca e a região mais interna de um roxo intenso, escuro e de textura aveludada (Figura 1).

As flores são grandes, possuindo, em média, 8,2 $\pm 0,4 \mathrm{~cm}$ de largura e $7,7 \pm 0,7 \mathrm{~cm}$ de comprimento. As sépalas possuem um formato lanceolado de ápice obtuso com margens recurvadas de ondulação muito fraca. As pétalas laterais são elípticas de ápice agudo, apresentando ondulações nas margens. O labelo mede 4,2 $\pm 0,2 \mathrm{~cm}$ de largura e $4,8 \pm 0,3 \mathrm{~cm}$ de comprimento, sendo levemente ondulado na margem. As plantas apresentam florescimento intenso com em média 34 flores por pseudobulbo, tendo a floração duração de aproximadamente 20 dias.

\section{MANUTENÇÃO E DISTRI- BUIÇÃO DE PLANTAS}

Plantas da cultivar UEL 8 são mantidas pelo Departamento de Agronomia da Universidade Estadual de Londrina, C. Postal 6001, 86051-990 Londrina-PR em casa de vegetação com cobertura plástica e sombrite de $50 \%$ de sombreamento. São micropropagadas via cultura de gemas axilares e plantadas em vasos plásticos contendo como substrato uma mistura de fibra de casca de coco com casca de pinus $(1: 1, \mathrm{v}: \mathrm{v})$.

\section{REFERÊNCIAS}

CARDOSO JC. 2010. Laeliocattleya 'Brazilian Girl Rosa': cultivar de orquídea para cultivo em vaso. Horticultura Brasileira 28: 378-381.

FARIA RT; ASSIS AM; CARVALHO JFRP. 2010. Cultivo de orquideas. Londrina: Mecenas. 208p.

FARIA RT; TAKAHASHI LSA; LONE AB. 2009. UEL 6: nova cultivar de Dendrobium. Horticultura Brasileira 27: 114-115.

FARIA RT; TAKAHASHI LSA; LONE AB; BARBOSA CM; TAKAHASHI A; SILVA GL. 2011. UEL 7: nova cultivar de Dendrobium. Horticultura Brasileira 29: 441-442.

IBRAFLOR - Instituto Brasileiro de Floricultura. 2013a, 15 de janeiro. Release imprensa. Disponível em http://www.ibraflor.com/ ns_exportacao.php/

IBRAFLOR - Instituto Brasileiro de Floricultura. 2013b, 01 de fevereiro. Critério de Classificação Dendrobium Vaso. Disponível em http://www.ibraflor.com/p_qualidade.php/

JUNQUEIRA AH; PEETZ MS. 2011. Panorama socioeconômico da floricultura no Brasil. Revista Brasileira de Horticultura Ornamental 17: 101-108.

MURASHIGE T; SKOOG F. 1962. A revised medium of rapid growth and bioassay with tobacco tissue cultures. Physiologia Plantarum 15: 473-479.

REGO-OLIVEIRA LV; FARIA RT. 2005. In vitro propagation of Brazilian orchids using traditional culture media and commercial fertilizers formulations. Acta Scientiarum 27: $1-5$.

SUTTLEWORTH FS; ZIM HS; DILON GW. 1994. Orquídeas: guia dos orquidófilos. Rio de Janeiro: Editora Expressão e Cultura. 158p.

TAKANE RJ; YANAGISAWA SS; PIVETTA KFL. 2010. Cultivo moderno de orquideas: Cattleya e seus hibridos. Fortaleza: UFC. 179p. 